\title{
MAIS UMA NARRATIVA ANTES DE ACABAR O MUNDO (ENSAIO SOBRE O TEMA DA VIAGEM EM MURILO RUBIÃO)
}

\author{
Hermenegildo José Bastos
}

\begin{abstract}
RESUMO: In murileon's fiction geography, the mountain is opposed to the sea. The characteres are former sailors or sailors descendents. The nostalgia for the sea relates to the action and bravery of the past. In the narrative's present, they dwell in country little towns. They move to the big cities or they wait for its representatives to come and civilize them. The train was substituted for the ship, each one representing one step in capitalism history: the Iberian and British expansion. The narration of the colonial adventure takes place. The fantastic writing reveals the ghosts of the modernity adventure, who wander between past and present. The most remote layers of the memory of this adventure are the ones of the little towns, and the most recent, the ones of the big cities. Different ways of production are confronted with different ways of survival. The narrator's bad faith denounces his complicity in power games.
\end{abstract}

PALAVRAS-CHAVE: Murilo Rubião, fantástico e modernidade periférica, rotas de viagem.

Hermenegildo José Bastos é professor na Universidade de Brasília 
"Concebem-se geralmente as viagens como um deslocamento no espaço. É pouco. Uma viagem se inscreve simultaneamente no espaço, no tempo e na hierarquia social. Cada impressão só é definível relacionandoa solidariamente com esses três eixos, e como o espaço possui sozinho três dimensões, seriam necessárias ao menos cinco para se fazer da viagem uma representação adequada.” (LÉVI-STRAUSS, 1957, p. 85)

Na ficção de Murilo Rubião, escritor mineiro "agoniado nas fraldas da Mantiqueira", como o narrador de "Ofélia, meu cachimbo e o mar", a geografia é a das cidades do interior. A ausência e o desejo do mar são marcantes. É o próprio mar que viaja no desejo dos personagens. Como nos maremotos e terremotos, rearrumam-se os espaços e territórios. Em "Bárbara", a personagem pede o mar. Em seguida, e com mais modéstia, pede um navio. Para atender ao seu pedido, o narrador providencia o desmonte do navio e a sua viagem de trem até o interior. Em "Epidólia", Manfredo estranha que a sua cidade tenha mar. O gerente do hotel explica: "Antes eram três localidades distintas. Natércia, Pirópolis e a Capital. Tendo se expandido, encheram os vazios, juntando-se umas às outras. Com Pirópolis veio o mar". Gostaríamos de situar o epicentro desses deslocamentos de terra e mar. Mas isso os contos não revelam. Na verdade, a explicação do gerente do hotel não satisfaz. Manfredo sente-se enganado, assim como o leitor. Toda explicação está desqualificada.

O hotel é um lugar de trânsito. Nele habita Epidólia. Mas também a casa dos tios de Manfredo é uma pensão. Aí, as pessoas podem ser hoje as mesmas de ontem, mas têm outros rostos e nomes. Vêm e voltam. Apenas a estranheza permanece.

Objeto do desejo, o mar não liberta, suas rotas são as da escravidão. A memória dos que vieram do mar se perde na escuridão das moles d'água, onde a consciência do narrador distingue gemidos de gente.

Os personagens vivem em trânsito, são viajantes ou se reportam a viagens, integram o cortejo do comércio entre as cidades. De Acácio, de "Memórias do contabilista Pedro Inácio", diz-se que "Tinha um aguçado instinto de viajante que o levava a perseguir as mulheres onde quer que elas fossem" (RUBIÃO, 1998, p. 108). O seu antepassado, Basílio da Câmara Bulhões e Couto, piedoso bispo, quando vinha de volta das Índias para Portugal, foi assaltado por piratas que o levaram para a China.

É uma viagem acidentada, de crimes e sofrimento. Uma viagem bem organizada, contudo, e que não acontece por acaso, mas seguindo ditames que, nem sempre claros para os personagens, atormentam o narrador. Nesse sentido, chega a ser um paradoxo que a viagem ao mesmo tempo se complete e se interrompa no meio do caminho. A projetada máquina se instala, cresce, propaga-se, fechando todas as saídas. Quanto ao 
personagem, porém, ele é jogado num caminho de transição que não se completa, como um destino que muda e se perpetua na medida mesma em que aparenta mudar.

Os personagens são viajantes, sim, mas viajantes a meio-caminho entre alguma coisa que ficou pra trás e não pode ser recuperada e uma outra que estaria à frente, inacessível. As histórias engrossam o volume da coleção de fracassos, aumenta (e dá variedade a) o álbum de viagens.

A tudo isso é preciso acrescentar ainda outro dado: a viagem inconclusa se propaga como um vírus, instala-se na estrutura dos contos. Os contos são reescritos, outra vez publicados, às vezes com outros títulos.

Os personagens migram de um para outro conto, ou, no interior do mesmo conto, trocam de nome. A mobilidade no discurso combina-se com a mobilidade na história. A literatura é mais um dos espaços de intensa mobilidade. Há, no discurso como na história, uma constante ameaça. Tudo é estranho... e perigoso. Nada é confiável.

Tanta mobilidade, porém, não representa mudança efetiva. Tudo se transforma para permanecer igual, o outro é só uma variação do mesmo. Freud (1954) localizou a origem do fantástico no automatismo da repetição. Benjamin (1985) vê na repetição a marca do mundo moderno, o da produção de mercadorias. Para mudar, seria preciso escrever uma outra história, deve pensar o leitor.

Um trem cruza os contos, ele também metamorfose, transformação de um navio, não de um navio qualquer, mas de um navio negreiro que, metamorfoseado em trem, adentra o interior do país, demarcando territórios.

A viagem já não é meio ou caminho, mas fim em si mesma. Torna-se objeto de coleção, e de instrumentalização, como em "Teleco, o coelhinho".

Aí, encontramos o narrador muriliano mais uma vez às voltas com o mar. No início do conto, ele está "frente ao mar, absorvido com ridículas lembranças". A narrativa tem início já quando os acontecimentos anteriores caíram na desmemoria. As lembranças são ridículas, mas o leitor não tem acesso a elas. Elas são indisponíveis também para o narrador. Contudo, os eventos narrados vêm repisar velhas histórias. O mar está carregado de histórias e estas continuam terra adentro.

Uma voz retira o narrador da sua contemplação frente ao mar. Seria possível uma outra viagem, como um percurso para a alteridade, uma outra viagem que não fosse apenas mais um selo na coleção? É a voz de Teleco, o coelhinho. O narrador se comove com o "jeito polido de dizer as coisas" do coelho, dá-lhe o cigarro que lhe fora pedido e abre espaço para que o coelhinho também possa ver o mar. Tornam-se amigos, e o 
coelhinho passa a lhe contar "acontecimentos extraordinários, aventuras tamanhas".

Para ser o narrador dessas histórias, Teleco, ser protéico, precisa ter a idade do mar, ou, mais precisamente, a idade da viagem da colonização. As histórias que, segundo o narrador, Teleco the conta não chegam ao leitor. O narrador, por sua vez, conta-nos uma história insólita ao lado de uma história comum. Insólita é a história do coelho que fala, transmuta-se e, por fim, ao tentar atingir a sua humanidade, morre no colo do narrador: "No meu colo, estava uma criança encardida, sem dentes. Morta". (RUBIÃO, 1998, p. 152) Comum é a história que se repete em todos os contos, a história da impossibilidade de mudar o destino.

A melancolia do narrador pelo mar é a de um velho marinheiro, absorvido agora pelas suas coleções, pelos selos, como uma coleção de poemas, um florilégio. Na melancolia confundem-se a literatura com o mar, com sua dose de ridículo. Como uma reescrita de um romance de viagens. Teleco é uma figuração de Proteu, é um prisioneiro do narrador. A arma de Teleco, como a de Proteu, é transformar-se continuamente de modo a fugir de quem lhe determina revelar o passado e o futuro: como começou a história e como continua? Qual o significado deste caminho que em certo momento passou a ser o nosso, tendo submetido ou mesmo abolido todos os demais?

Os eventos narrados são os da agiotagem, da polícia e do espetáculo. Tendo chegado à maioridade, Teleco, agora Barbosa, é expulso de casa e passa a ganhar a vida como mágico de circo. A capacidade de se metamorfosear comercializa-se, ou melhor, é desde sempre a maleabilidade da mercadoria. Não que o projeto humano de Teleco, na verdade do narrador, tenha se frustrado. O que se coloca é mais grave: da maneira como vem formulado, esse projeto é já uma manifestação do mundo da mercadoria, que é o espetáculo.

Selos viajam o mundo, franqueiam a postagem das correspondências. São marcas de distinção, sinais de estirpe. Senhas de acesso ou proibição. Legitimam documentos. São carimbos da burocracia, sinetes e chancelas de reis e nobres, legitimação das moedas.

Selo vem do latim sigillu. Carrega consigo o sentido de algo sigiloso e, em certas circunstâncias, escuso. Temos, por um lado, a viagem que os selos fazem ou de que são a lembrança melancólica; por outro, o selo como sinal de poder, ou ainda, como sinal da viagem das viagens - a da colonização.

A coleção do narrador conta com exemplares raros. Álbum é lugar de coisas de destaque, distintas, assinaladas, como fetiches. Por isso, se o álbum é forma de memória, é-o também de desmemoria, como uma 
coleção de fantasmas. A memória não está disponível. O leitor continuará sem saber quais os negócios de família e quais as ridículas lembranças. Também em "A fila", a prostituta Galimene, "filha de marinheiros, nascida nas docas", diz que conhecia "uma porção de histórias marítimas", mas estas também não chegam ao leitor.

Neste trabalho, procuro estabelecer um elo entre as histórias que nos contam os narradores (narrativas da impossibilidade de mudar o destino) e aquelas que eles e os demais personagens sonegam. A hipótese é a de que as histórias narradas são fragmentos de uma só história sonegada, como uma metanarrativa da dominação. As primeiras são narradas de "jeito polido", literário, como se fossem estetização da segunda. O escritor manifesta sua má consciência ao assumir a sonegação ou escamoteação como elemento constitutivo dessa escrita. O literário está comprometido com aquilo que estetiza. Nesse sentido, a ficção muriliana narra a aventura literária como cúmplice da colonização. Estetização da violência, como n' "Os três nomes de Godofredo" e n" "A casa do girassol vermelho".

$\mathrm{Na}$ verdade, é da literatura que aí se trata, da viagem literária e do seu viajante, o escritor. Para o personagem-artista de, por exemplo, "O exmágico da Taberna Minhota" ou "Marina, a intangível", a arte/literatura é magia decaída, incapaz de mudar a realidade e por isso mesmo comprometida com aquilo que ela não pode mudar. A analogia entre o escritor Murilo Rubião e o narrador-personagem de "Marina, a intangível" tem sido observada pelos estudiosos. (Cf. SCHWARZT, 1981)

Em "Marina, a intangível", a viagem é de casa para o jardim - um movimento dentro do espaço privado, familiar e religioso-, ou do jornal para a capela - um movimento de volta do espaço público para o mundo religioso. O personagem-escritor José Ambrósio lamenta a esterilidade e fala do esforço em enfrentar o papel e escrever. Mas o esforço é vão. Assim também ocorreria com Murilo Rubião, afirma Jorge Schwarzt.

O crítico assinala ainda que em Murilo a narrativa é arbitrária e, como tal, não pode dar conta da realidade que quer representar. As alterações e reescritas não levam a tornar a narrativa mais representativa. Também não visam aperfeiçoar por aperfeiçoar. É como uma condenação.

O desenvolvimento da comunicação escrita está ligado a formas modernas de espaço que opõem o público ao privado. A escrita e a leitura silenciosa substituíram a escrita em voz alta da Idade Média. São formas do individualismo moderno, do homem que, solitário, se entrega ao "mundo interior" da subjetividade. O mundo da escrita (da literatura) é o da danação. Não que a oralidade seja a pureza a todo custo - em Murilo, a oralidade é um sussurro, sua força é a mesma da voz de um fantasma. É quase inaudível. (A voz de Teleco, já no início do conto, "era sumida, 
quase um sussurro").

O protagonista de "Marina, a intangível" é um jornalista. O caminho do jornal (escrita corriqueira, profana) para a capela (onde se construiria o poema, escrita sagrada) seria a grande viagem. A história desenrola-se na casa, no jornal, na capela dos capuchinhos, no jardim. A casa, como espaço privado por excelência, estende-se até o jardim. Por oposição à praça, o jardim é um lugar sagrado, a morada de um deus. O caminho sem volta da escrita sagrada para a escrita profana é o desvão por onde transita José Ambrósio.

Por fim, o poema é feito sem palavras, feito de "pétalas e de sons estúpidos” (RUBIÃO, 1998, p. 85), alcançando sua forma para além do papel: "Os impressores, caminhando com o auxílio de compridas pernas de pau, encheram de papel o quintal”. (RUBIÃO, 1998, p. 85)

Autor, narrador e personagem vivenciam a aporia da modernidade. Mas é uma viagem sem volta, nada aí pode nos levar a pensar em um retorno a um passado místico e religioso.

Personagens atravessam o mar transportando mercadorias ("Ofélia, meu cachimbo e o mar", "Memórias do contabilista Pedro Inácio"); outros vieram do mar, mas o trazem ainda no espírito ("Epidólia"); personagens vão do mar em direção ao interior ("Bárbara"); outros se locomovem de trem para nenhum lugar ("A noiva da casa azul", "A cidade") ou de carro, também para nenhum lugar ("O convidado") etc. Os que vieram do mar são ex-marinheiros, prostitutas, ou desempenham papel de comando dentro de uma máquina de poder. O leitor é compelido a compartilhar a frustração da transformação, buscada, mas impedida. A luta já não é senão do leitor.

Em "Bárbara", com vimos, é o navio mesmo que viaja, e viaja de trem. O roteiro do mar é o da mercadoria. A personagem que a tudo devora, que tudo consome, afirma ser o navio "a coisa mais bonita do mundo". A beleza é, então, a aparição do horror.

Bárbara é apenas um nome, ou o nome, posto que dá título ao conto e é o único nome da história. Não é o nome de alguém, mas um índice do fenômeno fantástico. ${ }^{1}$ De fato, não há uma pessoa chamada Bárbara. O narrador, sim, é que é levado a confrontar-se com o fenômeno.

Bárbara devora as coisas, acrescenta-as ao seu corpo, que se avoluma "à medida que se ampliava sua ambição" (RUBIÃO, 1998, p. 33). É uma hipérbole. Como tal, é um gigante que parece ter saído das páginas da literatura infantil, que se alimenta de coisas e de gente. É a

${ }^{1}$ Para o conceito de fenômeno fantástico, cf. Malrieux, 1992. 
palavra-monstro. Suprime o mundo. Atrás da palavra bárbara há uma ausência fantasmática: tudo foi aprisionado na órbita do consumo. O narrador não lhe oferece resistência. Ele não é o herói em luta contra um ser maligno. Parece ser um instrumento de Bárbara, que lhe seduz e termina por lhe quebrar a resistência.

Bárbara é voraz. O seus pedidos são líricos e românticos: ela quer o oceano, a árvore, o navio, a estrela. A beleza aí está para ser consumida. O narrador viaja em busca do que ela lhe pede. E os pedidos se encadeiam dentro de uma lógica perfeita. São, como ela, hiperbólicos. O narrador os substitui por representações, metáforas, metonímias. Na verdade, manipula-os. A parte representa o todo: o oceano é substituído por uma garrafa contendo água do oceano, o baobá por um galho. Ela se maravilha com a garrafa, mas não se satisfaz com o galho. O baobá então é retirado do solo para satisfazê-la e morre.

Na palavra baobá, a última sílaba repete a primeira. A hipérbole repetitiva, em vez de fazer aumentar, faz reduzir. A condição para que Bárbara engorde é que o mundo emagreça, ou mesmo, suma. A morte do baobá é o seu aprisionamento pela linguagem, mas pela linguagem do conto que representa a própria arte enquanto mercadoria.

Bárbara pede um navio. Desmontado, ele é transportado no trem até à cidade. $\mathrm{O}$ filho de Bárbara não compreende a razão de tantos e inúteis apitos de trem. A razão escapa ao entendimento. Ela se mudará para o navio, assim que ele for remontado. Desmontar e remontar a nave que, mesmo em terra firme, continua a sua viagem. Em seguida, e por fim, Bárbara pede uma estrela, romântica e lírica como a arte pronta para o consumo.

Por aí podemos ver que o narrador não é bem um instrumento de Bárbara como aparenta. Ela, sim, é que é, como Teleco, como Ofélia, projeção do narrador. $\mathrm{O}$ que lemos é a história do narrador confrontado com o fenômeno fantástico, e esse fenômeno é o da palavra "bárbara", ou a história da escrita de "Bárbara", o fenômeno que é escrever.

É a questão da palavra aprisionada, da palavra sem poder de mudar a realidade, da palavra como elemento de instrumentalização. Esse é o drama do narrador. O personagem, por sua vez, é o instrumentalizado. Bárbara, Ofélia e Teleco (mas também Pererico de "A fila") são os seres impossibilitados de empreender a viagem efetiva, a da transformação verdadeira. Transformam-se, mas em selos das coleções do narrador.

O desmonte do navio assinala, não o fim da aventura colonial, mas a sua atualização. Um reajuste na máquina mercantil. Os personagens são ex-marinheiros. Hoje, são funcionários da estrada de ferro, e viajantes ou forasteiros. O trem se incumbe da expansão da aventura colonial. Às 
vezes, apenas se ouve ao longe o apito do trem, que lembra aos moradores da colônia agrícola que "Além de nós, havia no mundo mais alguém". (RUBIÃO, 1998, p. 23)

Levados para a serra, os personagens relembram-se do mar. No mar estavam a glória, as viagens, as descobertas, as conquistas, a força e o poder. Os ex-marinheiros trazem o mar tatuado no corpo, como um fetiche. Em "Epídólia", da barba do velho marinheiro Pavão pendem moedas. Em outros casos, narrador e personagem são um só, mas estrategicamente. $\mathrm{O}$ mesmo eu se desdobra em observador e observado, punidor e punido. O narrador conta a sua própria história ("O ex-mágico da Taberna Minhota") como aquele que internalizou a instrumentalização. É nesses casos que os contos de Murilo lembram mais de perto um poema lírico. Então, a viagem é a do eu em direção ao seu próprio abismo. De qualquer forma, a história que lemos é a do eu-narrador. A outra, a do eu-narrado, cabe ao leitor construir, como uma outra história e uma História outra, uma narrativa que não cabe nessa moldura.

A história do narrador é a de alguém que lida com a linguagem, que tem o poder de linguagem, mas que ao mesmo tempo sofre o poder da linguagem. Se assim é, o espectral está no ato de narrar entendido como forma de controle e manipulação. O que seria, inicialmente, o desejo de Bárbara, é agora a sua representação ou instrumentalização, sua degradação em elemento de consumo. Os leitores não têm conhecimento do desejo de Bárbara, como não têm acesso às histórias de Teleco ou Galimene. O desejo é o irrepresentável, aquilo que não tem espaço no universo narrado.

Os contos narram uma só viagem. Os acontecimentos se repetem, como numa rearrumação sem fim. O fim ansiado nunca é alcançado. Os personagens, depois de migrarem de um para outro conto, são obrigados a viver a mesma situação. Carregam consigo a consciência dolorosa da mesmidade. Nem a morte os salva, porque não podem ser sepultados ("O pirotécnico Zacarias"). A morte é mais uma das metamorfoses do mesmo. A tudo acompanha a má consciência do autor-narrador, cujo trabalho é rearrumar a história e manipular os personagens como se bonecos ou autômatos, mortos-vivos, que não podem ser sepultados e devem refazer outra vez e sempre os mesmos périplos diabólicos.

Nas metamorfoses, viajamos até os limites do humano. Alfredo, Ofélia e Bárbara são inumanos, ou quase. Xixiu e Surubi são subumanos. Teleco e os dragões (de "Os dragões") tentam atingir a humanidade, empreendendo a viagem sob o comando do narrador - a viagem da colonização.

N' "'A diáspora”, Roque Diadema, o invasor, é um engenheiro; n' 
"O edifício", João Gaspar é o engenheiro responsável pela construção diabólica; em "A noiva da casa azul", o narrador-protagonista é tomado pelo engenheiro que deveria dirigir os trabalhos de recuperação da estrada. Também a educação é uma forma de engenharia, a que constrói pessoas submissas ("Os dragões"). A engenharia literária também produz os seus concretos, espaços onde só há dentro ("Os bloqueios"). Os personagens são professores, padres, jornalistas, poetas, médicos, advogados, delegados. Os contos aludem aos romances de formação, ao aniquilamento da infância em prol da civilização. Os nomes de mulher assinalam prostitutas e bruxas. Viegas, de "A cidade", ressurge em Galimene, sedutora de Pererico em "A fila".

A história se perpetua. E se o fim de "Petúnia" não é o fim do pesadelo de Éolo é porque o pesadelo continua em outro conto. A danação é tanta que, dentro de um mesmo conto ("Os três nomes de Godofredo"), o personagem muda de nome, perde a memória, mas deve assassinar sua esposa mais uma vez (e esta, que também muda de nome, deve ser sempre outra vez assassinada). Os filhos de Aglaia e Colebra, em "Aglaia", nascem em ninhadas, umas após as outras, indefinidamente. A saída estaria no pirotécnico Zacarias, que a certa altura lamenta: "Não fosse o ceticismo dos homens, recusando-se a aceitar-me vivo ou morto, eu poderia abrigar a ambição de construir uma nova existência". (RUBIÃO, 1998, p. 31)

A metanarrativa da colonização (cf. EAGLETON, 1998) é uma metanarrativa não incluída por Lyotard (1986) no rol daquelas tidas como legitimadoras do saber e do poder. Observe-se, porém, que também o relato global e do colonialismo se apresenta como redentor: a colonização seria a narrativa da viagem da civilização, que abriria para os povos incultos, bárbaros e selvagens - os não-europeus - o caminho para a humanização.

Metanarrativas são para Lyotard mitologias universais, isto é, grandes narrativas que subordinam, organizam e explicam outras narrativas. São teleológicas: em nome de algum supremo para a humanidade, elas subordinam os desejos, anseios, fins, experiências, a um sentido último que, por isso mesmo, é opressor. Em nome das metanarrativas foram cometidos numerosos crimes e massacres.

Ora, a ficção de Murilo Rubião não é uma filosofia da história, mas empreende uma releitura da metanarrativa bíblica, que é a primeira e talvez a mais forte das metanarrativas ocidentais. Questiona também a metanarrativa da emancipação, os ideais de justiça e amor encarnados na figura meiga e terna de Teleco ou ansiados por Zacarias.

A metanarrativa da colonização pode ser lida em todos os contos como a história escamoteada (estetizada) pelo narrador. São negócios de 
família, aqueles mesmos que atormentam o narrador de "Teleco, o coelhinho" e reaparecem em "Ofélia, meu cachimbo e o mar" e "Memórias do contabilista Pedro Inácio".

"Ofélia, meu cachimbo e o mar" gira em torno de uma história de família, "episódios da crônica de minha família ou do mar". O narrador, tendo à frente "o oceano enegrecido pela noite", gosta de contar a Ofélia a história de marinheiros, navios negreiros, piratas, saques e tráfico de escravos. O passado da família fora escrito no mar pelo seu antepassado, o bisavô. No presente da narração, as moles d'água encobrem algo no mar, sepultam o que não é para ser visto. Já as sirenes das naves "cortam a noite como gemidos de homens que se perderam em águas distantes". (RUBIÃO, 1998, p. 114)

A história explora uma duplicidade: por um lado, a expressão da melancolia, que assume um contorno lírico (o mar, a varanda etc.), de outro a narrativa da viagem da crueldade (os saques, o tráfico de escravos, a coisificação). Paradoxalmente, o lirismo da nostalgia convive com o mundo prosaico do presente, um mundo pobre de aventuras, enquanto a viagem da crueldade é o conjunto de eventos fortes, do passado rico de ações.

Com a abolição da escravatura, para os descendentes de José Henriques Ruivães, restam as lembranças do passado de ação. Tornaramse meros colecionadores. Selos e estampas e lirismo. O diabólico e o perverso da antiga ação quase não se deixam ver nas coleções, nos florilégios. $\mathrm{O}$ gesto do colecionador pretende ser apenas estético.

O prazer do narrador em falar para (não conversar com) Ofélia, eis o princípio da estesia. Ela continua no olhar de Pedro, que vê as moles d'água e o que elas ocultam - um passado de crimes. Por fim é levada a conter-se pelos sons das sirenes-das-naves-gemidos-de-homens, que são os remorsos do narrador. São o som que o mar lhe devolve. Esta seria a resposta que lhe daria Ofélia se tivesse voz.

Ofélia de fato não tem existência na narrativa, mas é um contraponto ao discurso lírico do narrador, um lugar de materialização da voz não ouvida. O que aparenta ser um diálogo é um monólogo. O narrador, entretanto, pressupõe um leitor. Ofélia é, assim, um obstáculo à narrativa. O narrador deve contorná-lo. Ele precisa ser convincente sobre seu passado de glórias ("Sinto que não fui convincente e insisto com mais vigor: Ele existiu, juro.” (RUBIÃO, 1998, p. 118) Como isto não se dá, a história não se fecha. $\mathrm{O}$ narrador confessa que está delirando, mas isto tampouco convence. Assim, estabelecendo um contraponto para o narrador, Ofélia é a instância narrativa por meio da qual o leitor pode oferecer resistência às empulhações do narrador. O silêncio é a possibilidade de mil palavras que se oferece ao leitor real. 
Com isso, os remorsos do narrador ganham um lugar no texto, um papel na estrutura narrativa. São, assim, lançados para fora da consciência do narrador, o que evita que o conto descambe para o maravilhoso. ${ }^{2}$

Como instância discursiva, Ofélia (da mesma forma que Teleco) tem conhecimento da história que, entretanto, não revela. Na narrativa há lacunas, que o leitor, mais que preenche, conecta. As lacunas revelam traços não explicitados. A essa dimensão não formulada do texto, Iser chama negatividade. A negatividade, embora não formulada pelo texto, constitui o impulso fundamental na comunicação literária. Como tal, ela pode ser experimentada, mas não explicada. Dentre as suas características, assinaladas por Iser, vamos nos concentrar em uma.

A literatura, diz Iser, é um repertório de exemplos “de infortúnios e fracassos, aspirações destruídas, esperanças arruinadas, testemunhando a negatividade dos esforços da humanidade e a deformação desta última." (ISER, 1999, p. 32) Daí que a leitura só se realize à medida que faz emergir o avesso do mundo representado no texto, com seus fracassos e deformações. O leitor é levado a conceber a causa subjacente ao questionamento do mundo.

No conto, a coisa Ofélia, o inumano, é essa negatividade. Coisa, porque escapa à possibilidade de formulação. $\mathrm{O}$ narrador termina por assumir que delira. Tudo que temos é o delírio, que também escapa à formulação.

Colecionadores são todos os descentes de José Henriques Ruivães. Eles colecionam escravos, navios e mulheres. O narrador, por sua vez, quando criança, colecionava pequenas embarcações que fazia navegar na banheira. Lirismo e crueldade se alternam acentuando o comprometimento da literatura com o poder e a violência. Verificamos, então, que a duplicidade referida é aparente: aquilo que o narrador conta não é uma história antiga do mar, é a história da colonização, que é atual. O lirismo é a crueldade. Em "Ofélia...", na melancolia do narrador, está o princípio da estesia como violência e remorso.

Melancólico é também o olhar de Pedro Inácio, preocupado em explicar a origem da sua calvície: será ou não hereditária? Em "Memórias do contabilista Pedro Inácio", o narrador lamenta não conhecer "suficientemente a minha família". (RUBIÃO, 1998, p. 105) É Dora, a personagem feminina, quem lhe revela "o motivo da minha irresistível atração pelo amor e pela contabilidade". A sua mania de escrever deve-se a um antepassado beberrão. Os bisavós morreram de cirrose hepática. Mas to-

${ }^{2}$ As diferenças entre o maravilhoso, o estranho e o fantástico foram estudadas por Todorov ( 1970). 
dos da família, exceto João Antonio da Câmara Bulhões e Couto, desapareceram vitimados pelo amor.

A história costura passagens da narrativa de viagens e colonização. Viagens de descobrimento. Piratas que raptam os passageiros e os levam para a China. Exotismo. O amor romântico outra vez não pode faltar. O tio padre apaixona-se pela exótica, paganíssima Lu-chu-tzé. Roubo e pilhagem dão um caráter espetacular aos eventos narrados. E o espetáculo é, no caso, a própria literatura. O tataravô Pedro Inácio, de quem o narrador herdara o nome, era um lírico. Amante das artes, recita os clássicos franceses, dá nome de pintor, músico ou poeta a seus escravos, conciliando o mundo da cultura artística, supostamente crítica, com a miséria da escravidão ${ }^{3}$. Pedro Inácio, como Teleco, é o homem espetáculo.

A certa altura, o narrador externa o seu receio de não terminar as suas memórias. A invenção do passado não se sustenta: "O homem põe e seus antepassados dispõem", diz ele, que, enfim, descobre que não é filho de seus supostos pais.

$\mathrm{O}$ narrador contabiliza os insucessos do amor e da literatura. $\mathrm{O}$ tio Paulo, a quem coubera as escravas como herança, dedica sua vida exclusivamente ao prazer sexual. No final da vida, é sustentado pelas exescravas e atuais prostitutas.

Também "A fila" narra "um assunto sigiloso", aquele que faz Pererico sair do interior, de trem, para a cidade grande. Ele precisa falar com o gerente da Companhia. Mas nunca é atendido. Entre ele e a gerência há o porteiro Damião, "um negro elegante", que tenta fazer com que Pererico conte-lhe o assunto que o trouxera à cidade. Pererico faz segredo do assunto, por isso é punido. Damião oferece-lhe dinheiro em troca da revelação do segredo, que Pererico recusa. Damião passa a contar com a ajuda de Galimene, a prostituta. Esta, sim, dá-lhe dinheiro. Mas Pererico continua se recusando a "revelar a todo mundo um segredo que não me pertence".

A quem pertence o segredo? À cidade pequena, entendida aqui como as camadas mais remotas da memória? "A fila" é um conto em que o poder do narrador se evidencia de modo especial. A voz que acompanha as desventuras de Pererico pretende ser neutra, até mesmo ausente. Contudo é a voz de alguém que se distingue do protagonista, e distingue-se porque dispõe de outras condições. No lugar de onde vem Pererico pasta o gado, as formas de produzir e consumir são outras que não as do narrador, nem as de Damião, o porteiro, funcionário burocrático numa moderna organização. Desde o início, o narrador de "A fila" (como também o de "Teleco,

${ }^{3}$ Esta parece ser uma situação definidora da literatura brasileira. Sobre isso, cf. Schwarz ( 1990). 
o coelhinho") sabe que o personagem está condenado ao insucesso. Ele não está livre de culpa. Também em "Bárbara", o narrador avalia de modo depreciativo o pedido da personagem: "Como poderia saber da beleza de um barco, se nunca tinha visto um e se conhecia o mar somente através de uma garrafa?" Em seguida, ele embarca outra vez para o litoral, fazendo uso de seu livro trânsito.

Manfredo também se desloca em busca de Epidólia, sua amada. Viaja no tempo-espaço. Mas de Epidólia só o desaparecimento é evidente. Fantasma é aquilo que desaparece e reaparece. $\mathrm{O}$ adjetivo substantivado "fantasmagórico", diz Bellemin-Noël, é a arte de pôr em cena os fantasmas. O fantasma está ao mesmo tempo ausente e presente, mas primeiro ausente: "é alguma coisa, mas não é em si mesmo; o fantasma torna-se meio para aparição daquilo que não é”. (BELLEMIN-NOËL, 1972, p. 3) Esta coisa, mesmo ausente, nos vê, ainda quando não a vemos. Derrida diz do espectro que "Esta coisa olha para nós, no entanto, e vê-nos não vê-la mesmo quando ela está aí". (DERRIDA, 1994, p. 22)

Epidólia "não resiste ao sortilégio do mar e a ele retorna sempre". (RUBIÃO, 1998, p. 177) Manfredo deveria procurar Pavão, pai-amante de Epidólia, num dos botequins da orla marítima. No trajeto, ele se convence da existência do mar, pois constata a ausência de vegetação, que ele notara na vinda. Encontra Pavão, objeto ao mesmo tempo de sedução e de repulsa, como o dinheiro, as moedas que lhe pendem da barba. O corpo sedutor e asqueroso do dinheiro, que é sem corpo, mas equivale a todos os corpos.

Retomando a hipótese, temos, por um lado, um conjunto de eventos efetivamente narrados, insólitos, mas verossímeis; por outro, temos uma história que nos é sonegada, embora se dê notícia de sua existência. Não que uma constitua a explicação da outra.

A questão pode se complicar se considerarmos que a negação da história não parece ter o mesmo sentido se se trata de um segredo mantido pelo personagem perseguido (Pererico, Ofélia, Bárbara, Teleco) ou se se trata de uma escamoteação por parte do narrador. Pense-se na viagem de Manfredo em "Epidólia". Todos na história parecem querer enganar Manfredo, principalmente Epidólia. ${ }^{4}$ Manfredo sai em busca das representações de Epidólia. (Cf. BASTOS, 1999) Nesse sentido, pode ser o próprio leitor procurando entender o conto, tomado como representação de algo. Ler Murilo é, assim, cair na cilada do texto, mais ou menos como Alexandre

${ }^{4}$ Lembre-se que a palavra grega dolio significa astuto. Aparece em Homero como um dos epítetos de Ulisses, e pode ter o sentido de dolo, embuste. CF. Brunel (1997, p. 899) 
Saldanha Ribeiro n' "Armadilha”.

N" "O bloqueio", o leitor é tomado inicialmente pela referência à dimensão espacial. O espaço vai aos poucos se fechando, isolando-se do resto do mundo. Ao mesmo tempo, entretanto, é o próprio mundo.

É uma narrativa em terceira pessoa, com um narrador-testemunha. Aquele que vive os acontecimentos leva o nome de Gérion. É ele que ouve os ruídos no edifício recém-construído. São vibrações de vidro, vêm dos pavimentos superiores e se confundem com o barulho produzido pelas raspadeiras de assoalho. Gérion sente-se ameaçado. Procura explicações para os acontecimentos com o síndico do edifício, que lhe diz tratar-se de "obras de rotina". Gérion ouve a máquina cortando "material de grande resistência". "Emitira a máquina voz humana?", ele pergunta (RUBIÃO, 1998, p. 250). A máquina trabalha lentamente aprimorando a obra. O pânico cede lugar ao fascínio. Gérion está fascinado pela máquina. Procura captar seus sons agrupados em escala cromática, "enquanto na sala penetravam os primeiros focos de luz". Mas a máquina se esconde, não permitindo que ele a contemple na plenitude de suas cores. A máquina destrói e constrói, sepulta a aura, mas ao mesmo tempo multiplica-a, diabolicamente é certo. O fascínio que ela desperta é o do horror. Reduz tudo a "um pó cinzento e fino". Arte sem aura, mas de intenso fulgor, como as luzes dessa máquina.

Aqui é leitor que transita do espaço como texto para o texto como espaço. A multiplicação da aura é também um dolo. A viagem que aí se narra é a da modernidade.

No meio de tudo, como epicentro dos terremotos, a questão da literatura, que é, à sua maneira, a viagem da modernidade. Como participante dessa viagem, Pererico preserva o silêncio, o segredo do que não lhe pertence. Pererico paga, como também Teleco e Ofélia, um alto preço por isso. Quanto ao autor-narrador, cabe considerar a sua ambivalência (que é a ambivalência da literatura): por um lado, o seu comprometimento com a narrativa da dominação - compromisso que se manifesta no ato de estetizar; por outro, o seu esforço por se aproximar do personagem. Com certeza é por isso que ele renega toda explicação, retoma, sempre mais uma vez, o mesmo enredo, antes que a história acabe.

\section{BIBLIOGRAFIA}

BASTOS, Hermenegildo. O guarda-roupa do fantasma ou a astúcia da representação em fuga. Para uma leitura de "Epidólia" de Murilo Rubião. In: Cerrados, n. 9, ano 8, 1999. 
BELLEMIN-NOËL, Jean. Notes sur le fantastique (textes de Théophile Gautier). Littérature, n. 8, 1972.

BENJAMIN, Walter. A obra de arte na era da sua reprodutibilidade técnica. In: Obras escolhidas. V. I: Magia e técnica, arte e política. São Paulo, Brasiliense, 1985.

BRUNEL, Pierre (org.). Dicionário de mitos literários. Rio de Janeiro, José Olympio; Brasília, EdUnB, 1997.

EAGLETON, Terry. As ilusões do pós-modernismo. Rio de Janeiro, Jorge Zahar Editores, 1998.

FREUD, Sigismund. Lo Siniestro. In: Obras completas, v. 17. Psicoanálisis aplicado. Buenos Aires, Santiago Rueda, 1954.

LYOTARD, Jean-François. O pós-moderno. Rio de Janeiro, José Olympio, 1986.

DERRIDA, Jacques. Espectros de Marx. O Estado da divida, o trabalho do luto e a nova internacional. Rio de Janeiro,

Relume Dumará, 1994.

ISER, Wolfgang. Teoria da ficção: indagações à obra de Wolfgang Iser. Rio de Janeiro, EdUERJ, 1999.

LÉVI-STRAUSS, Claude. Tristes trópicos. São Paulo, Anhembi, 1957.

MALRIEUX, Jean. Le fantastique. Paris, Hachette, 1992.

RUBIÃO, Murilo. Contos escolhidos. São Paulo, Ática, 1998.

SCHWARTZ, Jorge. A poética do uroboro. São Paulo, Ática, 1981.

SCHWARZ, Roberto. Um mestre na periferia do capitalismo: Machado de Assis. São Paulo, Duas Cidades, 1990.

TODOROV, Tzvetan. Introduction à la littérature fantastique. Paris, Seuil, 1965. 